\title{
A New Typology to Describe the Regional Differences in Swiss Labor Markets ${ }^{1}$
}

\author{
Matteo Antonini*
}

\begin{abstract}
The analysis of the Swiss labor market poses a methodological challenge. On the one hand, Switzerland is too diversified to be analyzed as a single socio-economic space. On the other hand, a high level of territorial fragmentation makes the use of administrative divisions methodologically weak. In this paper, we classify Swiss cantons into three types of labor markets: attractive, multicenter, and marginal. Our typology is based on a wide range of economic and labor market parameters, and can be a ready-to-use tool for further researches. Keywords: labor market, regional differences, Switzerland, typology, fuzzy clustering
\end{abstract}

\section{Eine neue Typologie für die Beschreibung regionaler Unterschiede im Schweizer Arbeitsmarkt}

Zusammenfassung: Die Analyse des Schweizer Arbeitsmarktes ist eine methodische Herausforderung. Einerseits kann die Schweiz aufgrund ihrer Vielseitigkeit nicht als einheitlicher sozioökonomischer Raum betrachtet werden. Andererseits schwächt die starke politischadministrative Fragmentierung die methodische Aussagekraft von Analysen auf regionaler Ebene. Der vorliegende Artikel teilt Schweizer Kantone in attraktive, multizentrische und marginale Arbeitsmarkttypen ein. Diese Typologie basiert auf einem breiten Spektrum von wirtschaftlichen und arbeitsmarktbezogenen Parametern und ist prädestiniert für die Anwendung in zukünftigen Studien.

Schlïsselwörter: Arbeitsmarkt, regionale Unterschiede, Schweiz, Typologie, fuzzy clustering

\section{Une nouvelle typologie pour décrire les différences régionales au sein du marché du travail helvétique}

Résumé: L'analyse du marché du travail helvétique pose un double enjeu méthodologique. D'une part, il est trop diversifié pour être analysé en tant qu'espace socio-économique homogène. D'autre part, l'utilisation de divisions administratives n'est pas pertinente d'un point de vue méthodologique en raison de sa forte fragmentation administrative. Cet article propose de catégoriser les cantons en fonction de leur type de marché du travail : attractif, multicentre ou marginal. Cette typologie se base sur un large éventail de paramètres économiques et liés au marché du travail, afin de constituer un outil pour les recherches à venir.

Mots-clés: marché du travail, différences régionales, Suisse, typologie, fuzzy clustering

University of Lausanne, NCCR-Lives, CH-1015 Lausanne, matteo.antonini@unil.ch.

1 This publication benefited from the support of the Swiss National Centre of Competence in Research LIVES - Overcoming vulnerability: Life course perspectives, which is financed by the Swiss National Science Foundation (grant number: 51NF40-160590). The authors are grateful to the Swiss National Science Foundation for its financial assistance. 


\section{Introduction}

Switzerland is a complex territory. The history of this country and the recent socioeconomic trends have created a very heterogeneous territorial structure both in the institutional set-up and in the socio-economic fabric. To some extent, this situation is present in almost every country, but the numerous territorial aggregations that lead to present day Switzerland, led to a federation of largely autonomous and heterogeneous areas. Switzerland has 26 main institutional territories (cantons), while other much bigger European countries are split into fewer areas: Germany has 16 main areas (states), France 18 (regions), Spain 17 (communities), Italy 20 (regions) and Austria, which has a similar territory and population to Switzerland, nine (states). The geographical variable is therefore complex to manage. For many studies, the cantons are too numerous and too small to be included in the analysis. In particular, this territorial set-up is a considerable obstacle when it comes to describing labor market characteristics that follow economic relations disconnected from the institutional borders. The creation of a typology grouping similar labor markets is a possible way to overcome this issue. This effort was already made in Swiss literature (e.g. Battaglini and Giraud 2003; Flückiger et al. 2006), but is limited to the analysis of specific socio-economic elements. A wide-range typology is absent. Consequently, current research widely uses different measures of geographic disparities both as explicative and control variables. The most frequently used measures rely on cultural variables (e.g. the prevalent language), or on the European Nomenclature of Units for Territorial Statistics (NUTS), known in Switzerland as "Vast Regions." These measures are used in research on economic and labor market topics, for example, gender-related wage gaps (Bertschy et al. 2014), the process of leaving the parental home (Wernli and Henchoz 2015), school-to-work transitions (Sacchi and Meyer 2016), and work-related life satisfaction (Lebert 2014). Despite the importance of these territorial divisions, a typology based on socio-economic variables would bring further value to the results of research that are focused on economic and labor market dynamics. The aim of this paper is to propose a typology that concisely describes the regional differences in the Swiss labor market in recent years (2008-2015). The proposed typology is based on a vast set of variables and can be used as a tool for the entire labor market and all the socio-economic studies that seek to integrate indicators of regional differences in their empirical analyses.

The paper is organized as follows: After a brief description of the Swiss socioeconomic context (section 2), we present the measures currently used to evaluate the differences in the Swiss internal labor market (section 3). In section 4, we introduce the data and the method used to create our typology. This typology is fully described and discussed in section 5. In section 6, we use data from the Swiss Household Panel to explore the heuristic power and to show a possible use of our 
typology. Finally, in the conclusion, we recall the procedure, the results, and the possible developments of our research.

\section{The Swiss socio-economic context}

Switzerland is quite a unique case in the European context. The institutional set-up is based on 26 federated states named "cantons." Despite the cantons losing a large part of their power after the passage from a Confederative to a Federative set-up in 1848 , the central government often provides only a general legislative frame, leaving its application to the cantons. We can call this institutional set-up "executive federalism," borrowing the term used to describe the application of the federal law on unemployment (Battaglini and Giraud 2003). Economically, Switzerland is a stable market that records a high (though not equally widespread) purchasing power and many business facilitations. Workers' protections are underdeveloped compared to other European countries. The OECD Employment Protection Legislation (EPL) Index records low values for Switzerland in almost all the components. In particular, the protection of permanent workers against individual dismissal is among the lowest of the OECD (OECD 2013). The economic fabric is also diverse. High-tech and international companies as well as highly specialized enterprises are present together with activities with a low added value. While some sectors are largely integrated in the international market economy, activities with a low added value (especially agriculture) are based on a national market and largely protected from foreign competition (Giugni et al. 2014). Unemployment was almost absent in Switzerland until the early 1990s. This very low level was maintained during the periods of crisis of the mid-1970s and early 1980s, by using the foreign and the female workforce as a buffer (Gerfin and Lechner 2002; Flückiger et al. 2006; Giugni et al. 2014). This varied economic and labor market structure makes Switzerland hard to situate in the most used categorizations of welfare states as it presents characteristics of different models (Bertozzi et al. 2005; Giugni et al. 2014). The strong participation of the population in the workforce, especially with regard to women and elderly workers (Le Goff 2005; OECD 2014), is similar to the Scandinavian countries, but the presence of working poor suggests a similarity with the Anglo-Saxon liberal labor markets. On the other hand, the education system in Switzerland is similar to other countries of the Germanic area such as Germany, Austria, and Denmark. All these countries have a dual education system that links vocational training and occupational placement in the labor market. This option is chosen by more than $60 \%$ of the young Swiss. 


\section{Theoretical frame}

\subsection{Epidemiologic perspective and rigid geographic divisions}

There are two main ways to deal with geographical variables: (a) adopt an epidemiologic perspective considering the diffusion of a phenomenon above a territory or (b) rely on rigid geographical divisions, and consider a territory as composed by homogeneous areas.

The last two decades saw several developments in the epidemiologic perspective. Among the major contributions, we find the "diffusion or contagion models" (Ward 2002), since the observations are conditionally dependent upon one another. We review alternative techniques for estimating this model, with special emphasis on recent advances using the Markov chain Monte Carlo (MCMC) and the "spatially autoregressive models" (Savitz and Raudenbush 2009). These models define the distribution of the variables referring to "metrical" measures (e.g. square kilometers) or to the distance from reference points. Using specific thresholds, the researcher creates small areas, which are then re-aggregated in bigger areas according to the research interests and independent from the institutional borders (Chaix et al. 2005). Different types of connections between areas can also be introduced to consider natural obstacles or other boundaries. These techniques are particularly useful to analyze spatial characteristics that are separated from administrative territories. The second approach relies on rigid geographical divisions. This is the "classical" way to study geography-related variables. It relies on typologies based on institutional or other divisions previously made for administrative or scientific purposes. In sections 3.2 and 3.3, we describe the institutional and variable-based typologies currently in use. In this paper, we follow this approach due to its flexibility and easiness to use in studies that are not specifically focused on the analysis of spatial divisions. As we intend our typology to be a tool for further analyses, the user-friendly dimension is essential. Nevertheless, we are aware of the limits of this technique (Chaix et al. 2005). Particularly, some assumptions have to be accepted. First, each territory is considered homogeneous concerning the considered variables. Second, the transitions from one territory to another are not gradual. There are no transitional areas. Third, each type is a simplified representation of reality. Any nuance is lost in favor of a homogeneous description. Fourth, the features of an area are not directly transferable to sub-areas or to the individual level. Otherwise, we are committing an "ecological fallacy" (Pintaldi 2003).

\subsection{Official divisions}

The Swiss administrative division is complex and relies on different criteria, depending on the purposes of the institutions that created them (see Schuler et al. 2005 for a review of Swiss administrative divisions). 
The main administrative divisions are the cantons. The country includes 26 cantons that vary largely in dimension and population. Some cantons are the size of small towns (e. g. Appenzell Innerrhoden), while others include only a city with its suburbs (e. g. Basel-Stadt or Geneva). Some cantons are vastly populated areas (e. g. Bern), while others refer to poorly inhabited alpine areas (e. g. Graubünden). On the political level, cantons have a large decisional autonomy. Even if the federal laws are the same for every territory, the actual policies may vary considerably. A good example is the application of the policies against unemployment. The normatives coming from the federal government are applied in different, often opposite, ways. Some cantons have very active policies focusing both on workers' reintegration and control over abuse, while others have a very light structure with almost no support or control (Battaglini and Giraud 2003). Despite its vast use in the literature, the institutional division based on cantons is sometimes hard to use in empirical analyses, due to the high number of units (26) and to the presence of very small groups. These limitations are particularly severe in sample-based analyses, as this division dramatically increases the possibility of having territories with very few or no individuals included in the sample.

Excessive heterogeneity and the high number of cantons are often overcome using another administrative division that groups the 26 cantons into seven "Vast Regions." This typology is widely used and follows the second level of the Eurostat's "Nomenclature of Units for Territorial Statistics" (NUTS). This division includes areas with a population between 800000 and three million inhabitants. The population size is the only criterion, but it is not applied strictly. Cultural and historical divisions are somehow respected as well as country borders. Consequently, two vast Swiss regions (Central Switzerland and Ticino) have less than 800000 inhabitants. Nevertheless, no economic or social variables are considered. This division has unquestionable advantages from an administrative and statistical point of view, as it relies on regions that are comparable in population size and are sufficiently vast to include the attraction areas around the biggest cities, which often go beyond cantonal borders. It is consequently also used outside the administrative context (e. g. Feld and Savioz 2000; Lebert 2014). Nevertheless, the imposed territorial continuity and the prominent role of population size over other characteristics are strong limits for the applicability of this typology in labor market studies.

\subsection{Labor market typologies made out of specific variables}

The analysis of regional differences in Swiss labor markets has recorded many contributions in the past decades, especially from an economic point of view (Flückiger et al. 1986; Joly et al. 1993; De Coulon 1999) and a sociological one (Bruttin 1997; Filippini 1998). In this section, I focus only on recent developments in this field of study. As these analyses rely on parameters that change over time, a commentary on old studies is hardly meaningful. 
A very influential analysis of regional differences in Swiss labor markets relies on the description of cantonal policies against unemployment (Battaglini and Giraud 2003; Giraud and Battaglini 2004; Perret et al. 2007). The authors define a typology that considers "on the one hand, active labor market programs aimed at supporting the reintegration of the unemployed with control measures designed to prevent abuse of unemployment benefits on the other" (Battaglini and Giraud 2003, 286). Unlike previous studies (e.g. Curti and Meins 1999; Giriens and Staufer 1999), this typology aims at the analysis of both the extension and the modes of cantonal implementation of the federal law. Four indicators are used to measure two dimensions called "reintegration" and "control." Reintegration measures the local application of the federal law and considers three dimensions: (a) the implementation of a "logistic," i. e. the organization of devices to analyze the needs of employers and the qualifications of job-seekers in order to organize specific training programs, (b) the implementation of experimental programs to develop federal norms, (c) the fulfillment of federal targets. Control considers how the cantons prevent and fight abuse. A single dimension, i. e. the number of penalties decided by cantonal offices, measures it. The results are summed up in Table 1.

Table 1

Categorization of Swiss cantons according to Battaglini and Giraud's reintegration/control model

\begin{tabular}{l|c|c|c}
\hline \multirow{2}{*}{ Control } & \multicolumn{3}{|c}{ Reintegration } \\
\cline { 2 - 4 } & \multicolumn{2}{|c}{ High } & Low \\
\hline High & Basel-Stadt & Uri \\
& Luzern & Bern & Obwalden \\
& Solothurn & Aargau & Nidwalden \\
& Graubünden & Glarus & \\
& Schwyz & Basel-Landschaft & St. Gallen \\
\hline Low & Jura & Geneva & Appenzell Ausserrhoden \\
& Valais & Neuchâtel & Appenzell Innerrhoden \\
& Ticino & Zug & \\
& Fribourg & Zurich & \\
& Vaud & & \\
\hline
\end{tabular}

Source: adapted from Battaglini and Giraud (2003).

Reintegration is considered high when at least one indicator is present. Otherwise, it is considered low. Control is considered high if the single indicator is fulfilled. Otherwise, it is considered low. Four types are defined:

1. "Maximalist" implementation: high reintegration and high control

2. "Partial, control-oriented" implementation: low reintegration and high control

3. "Partial, reintegration-oriented" implementation: high reintegration and low control

4. "Minimalist" implementation: low reintegration and low control 
Cantons in bold are fully representative of the group while cantons in italics are only marginally included. Schaffhausen and Thurgau are not present in the typology as data are missing for these cantons.

Not surprisingly, the Latin part of Switzerland, which is traditionally more progressive, is split from the rest of the country. The only exception is represented by the Zurich metropolitan area (cantons of Zurich and Zug). All the Latin cantons are included in the "partial, reintegration-oriented" group while the majority of the German-speaking cantons are in the "maximalist" cluster. Only some small cantons of the Germanic area are included in the remaining groups.

Alternative approaches to describe the regional differences in Swiss labor markets are present in a wide report called Analyse des différences régionales de chômage (Flückiger et al. 2006). This study summarizes some previous research (De Coulon 1999; Feld and Savioz 2000; Flückiger and Vassiliev 2002) and applies different approaches. First, it analyzes the Beveridge curve and the regional effect for each canton. This measure describes the independence of each territory from the national economic trend. A set of values is reported but a typology is not present. Second, the report considers the average exit time from a situation of unemployment. Three levels are introduced:

- Fast exit (Appenzell Innerrhoden, Basel-Landschaft, Basel-Stadt, Bern, Graubünden, Schwyz, Zurich)

, Intermediate exit (Glarus, Nidwalden, Obwalden, Schaffhausen)

, Slow exit (Geneva)

The other 14 cantons are missing. Together with these results, a more complete description is given by a typology considering two variables: unemployment rate and average unemployment length. Unemployment rate is considered high if it is included in the first quartile and low if it is included in the last quartile. The same distinction is applied to unemployment length. Five categories are therefore identifiable: high unemployment rate and high unemployment length (Geneva, Vaud, Neuchâtel, Jura and Ticino); low unemployment rate and high unemployment length (Aargau); high unemployment rate and low unemployment length (Valais); low unemployment rate and low unemployment length (Uri, Obwalden, Graubünden and Nidwalden); all the other cantons are in the intermediate group (medium unemployment rate and medium unemployment length). These categories are purely descriptive and only define the extreme cases precisely. To overcome these limitations, the authors propose a further typology based on individual characteristics and including some explanatory variables: activity before unemployment, age, sex, qualification and nationality. Five groups are defined:

, Group 1: Neuchâtel, St. Gallen, Thurgau, Vaud, Zurich

- Group 2: Basel-Landschaft, Fribourg, Schwyz, Solothurn, Zug

, Group 3: Appenzell Ausserrhoden, Glarus, Jura, Valais 
, Group 4: Aargau, Basel-Stadt, Bern, Ticino

, Group 5: Geneva, Luzern

Appenzell Innerrhoden, Graubünden, Nidwalden, Obwalden, Schaffhausen and Uri are not categorized due to data limitations. This typology is the most complete regarding the number and the type of variables used for the analysis. Nevertheless, it relies on individual-level variables and not on canton-level variables. This change in the level of analysis can lead to an "ecological fallacy" (Pintaldi 2003). Consequently, using these results to describe the differences among the cantons is rather dangerous. In unemployment-related topics, particularly, the link between individual job trajectories and the global labor market situation is not always strong (Oesch and Lipps 2012).

\subsection{A new typology to overcome some general limits of the literature}

All the introduced typologies suffer from at least one of the following three limitations. First, the number of variables used to describe the cantons is low (in many cases, just one variable is used). This leads to unidimensional descriptions, which give us profound but limited information. Second, the identified types are often too numerous. Even if these typologies simplify the information, the complexity often remains too high to be easily managed as an independent or control variable in other analyses. Third, the typologies often fail to categorize all the cantons. Due to a lack of information or due to the structure of the analysis (based on relative values), some cantons are left out of the typology.

Our proposal is to create a typology based on a large number of economic and labor market variables that reduces the territorial dimensions in few groups and that includes all the cantons. Cantons are chosen to be the base unit for three main reasons. (a) Cantons are the administrative level that actually perform labor market and economic policies. Consequently, this is the most-used level of analysis in unemployment, labor market and socio-economic studies. (b) Cantons are often the more precise available information about the residence and/or the place of work. Often, the town of residence is not available for reasons linked to the anonymization processes, especially in the case of small communities. (c) The information about the economic and labor market features of smaller administrative areas (e.g. municipalities) is often inexistent, especially for small towns or country areas.

\section{$4 \quad$ Data and method}

\subsection{Data and variables}

Our data stem from different periodical surveys conducted by the Swiss Federal Statistical Office (FSO) and the Swiss Federal Department for Economic Affairs. The 
results of these surveys are included in the FSO's interactive database (STAT-TAB). All the data and the variables are retrieved from this database. We want our typology to be descriptive of many socio-economic and labor market aspects of Swiss regions. For the selection of the measures to include in our analysis, we follow a criterion based on a theoretical reflection and previous literature. Unfortunately, time series of these data are not always available at the cantonal level, and we were not able to find a single year of reference for all the variables. Consequently, we decided to take the most recent value for each variable in order to have an updated portrait of Swiss economic and labor market structure. We have to rely on measures based on different years, from 2008 to 2015. This is not the optimal methodological solution, but the time span is small and the oldest measures refer to characteristics that are rather stable for short spans of time (i. e. the presence of high-tech companies). In addition, we analyzed the trend of much more volatile variables (e. g. GDP per capita). Obviously, the numerical values change during the years, but the relative position of each canton in the Swiss context remains rather stable. As our analyses are based on relative positions, the outputs are almost identical. Consequently, we posit that the variations given by the use of different time points that occurred in these years are marginal and do not affect our results. Nevertheless, similarly to what happens for other typologies, should our typology become an instrument for other analyses, periodical updates will be necessary to revalidate its structure. However, in absence of dramatic events (such as war or a generalized economic crisis), the economic structure of a region changes only in the medium-long term. Consequently, these updates will be necessary but not frequent.

The variables used to create our typology are split into two groups. The first refers to cantonal economy, the second to labor market characteristics. The economic variables include:

Gross Domestic Product (GDP) per capita in the year 2012. This information, although disputed (Stiglitz et al. 2010), is still a relevant overall measure of cantonal wealth and is widely used in reports and analyses (e.g. Goebel and Ehrensperger 2009; Jeanneret and Goebel 2012).

The variation of the Gross Domestic Product (GDP) per capita. Data refer to the period 2008-2012 and moderate eventual outliers linked to the 2012 measure.

The correlation between the trends of the cantonal and national Gross Domestic Product (GDP) per capita for the period 2008-2012. With this measure, we want to explore the connection between the national and the cantonal economy. This characteristic is crucial to define if an area is linked to the local economy or if it is framed in a vaster world economy. Despite the use of different indicators, previous contributions (De Coulon 1999; Flückiger et al. 2006) stressed the importance of measuring the independence of cantonal economy from national trends in order to identify the regional differences in the Swiss economic fabric. 
The Gini Index in 2010. This measure is not used in previous Swiss research. Nevertheless, it is widely used on the international level (e. g. Barro 2000; Kubiszewski et al. 2013) to complete the information given by the GDP. If GDP is an overall measure of wealth, the Gini index reports its distribution.

The percentage of Small and Medium Enterprises (SMEs) on the total in 2008. This is fundamental information on the local economic structure (Goebel and Ehrensperger 2009; Jeanneret and Goebel 2012).

Presence of high-tech enterprises on the total in 2008. High-tech enterprises are defined according to the criteria used in the official Nomenclature of the Economic Activities (FSO 2008). This element is one of the main indicators of the local economic structure (Goebel and Ehrensperger 2009; Jeanneret and Goebel 2012).

Global index of tax pressure referring to the year 2015. This measure completes the description of the economic structure and introduces an element linked with cantonal political choices. We chose this measure instead of others, as tax-related decisions have a long-term structure based on gradual changes.

The second group of variables refers to cantonal labor market characteristics:

Unemployment rate in 2015. This is among the major measures for labor market studies (Battaglini and Giraud 2003; Perret et al. 2007).

Youth unemployment rate in 2015. Alongside the general measure, we introduce youth unemployment, as this dimension is an index of the openness of the job market towards new workers, as well as of the efficacy of the connection between school and labor market.

Long-term unemployment in 2015. This is a specific sub-population of unemployed workers. This measure is one of the main variables used to understand the structure of the unemployment population (Sheldon 2013; Bonoli 2014).

Share of women in the labor market. It is defined as the percentage of women in the workforce in 2010. This measure is often present in labor market reports (e.g. Goebel and Ehrensperger 2009; Jeanneret and Goebel 2012), as it describes the openness of regional labor markets to non-traditional workers and measures the reactiveness to the increasing presence of Swiss women in the labor force.

The presence of cross-border workers in 2015. Swiss border areas are characterized by a high share of cross-border workers. Labor markets in these areas are different from the inner areas, as the presence of cross-border workers is linked to other labor market dynamics; unemployment in particular (De Coulon 1999; Feld and Savioz 2000). The attractiveness of the cantonal labor market, calculated with the net presence of national commuter workers, i.e. the difference between incoming and outgoing commuters. These data refer to the year 2014. Work-related mobility is a central topic in today's welfare policies (Guillet et al. 2016) and influences other elements of the labor market fabric (Ravalet et al. 2014). 


\subsection{Method}

Our typology is created using a cluster analysis on the values of the variables introduced in section 4.1 and with cantons as the unit of analysis. A possible division among the algorithms for clustering separates "hard clustering" from "soft (or fuzzy) clustering" algorithms. Hard clustering associates each unit to a specific cluster. The usual interpretation of hard clustering relies on a deterministic attribution and absence of outliers. Soft clustering, on the contrary, associates each unit to a vector of probabilities. Each probability refers to a specific cluster and a specific unit. They describe the likelihood of that unit to be included in that cluster and always sum to one. If a threshold for cluster membership is set, this likelihood describes both the position of each unit inside the clusters and the eventual presence of outliers.

We decide to use a fuzzy clustering technique, as it has a number of advantages. First, fuzzy clustering makes the discussion of outliers easier. Their presence is directly observable in the output, with no need for further analyses. This makes it possible to avoid having some units forced into a cluster only to respect the prefixed number of clusters. This feature is not opposed to our aim of creating a typology that includes all the cantons. Outliers are part of the results. We include them in the final results and consider them as special types of our typology. A second advantage of fuzzy clustering is the presence of a measure of the likelihood to be part of each cluster. This measure can be used to identify the most representative units of each cluster and to give a portrait of cluster composition. Thirdly, in fuzzy clustering, cluster membership is expressed by a percentage, i. e. a cardinal variable, instead of a categorical variable. This property facilitates the analysis of the relations among cluster membership and other variables.

Among the fuzzy clustering algorithms, we choose a method named Fanny (Kaufman and Rousseeuw 1990). The membership exponent is set to 2 and the dissimilarities are measured with Euclidean distances. These are the standard settings for this type of analysis (Kaufman and Rousseeuw 1990). The number of clusters is defined using a double parameter: silhouette analysis (Rousseeuw 1987) and Hubert C index (Hubert and Levin 1976). Both these indexes define the number of clusters that minimize the distance among units included in the same cluster and maximize the distance among units included in different clusters. The threshold is set to 0.5 . This means that each cluster collects only cantons that have a probability to be included in the cluster that is above the $50 \%$. Like all the thresholds, 0.5 is an arbitrary value. Nevertheless, this is a symbolic level, as it means that the likelihood to be included in a cluster is more than all the likelihoods to be included in all the other clusters combined.

Fuzzy clustering is an unusual procedure for this type of analysis. Consequently, we set up a test for it. We try to replicate our results using the same units of analysis and the same variables, but based on a more known and relied on procedure: the combination of Ward and Partition Around Medoids (PAM) clustering as 
described by Studer (2013). This algorithm is used only for the test, as it returns a less informative output (no outliers and no description of cluster composition). In order to make the results fully comparable, we change the procedure to include the units in the clusters. Only for this test, we remove the threshold. We use the highest probability recorded by each unit to decide which cluster it has to be assigned. Using these settings, the Fanny algorithm becomes a hard clustering procedure that gives results that are comparable with the Ward/PAM clustering.

Once the set of clusters is defined and the robustness of the procedure is tested, we describe the characteristics of each cluster, relating the probabilities to be part of a cluster with the values of the variables used to create them. As all the used variables are cardinal, we calculate the gross correlation using the Pearson's correlation index. This index varies from -1 to $1:-1$ means perfect negative correlation, 1 means perfect positive correlation and 0 means independence. Usually, absolute values greater than 0.7 are considered "strong" and absolute values between 0.3 and 0.7 are considered "moderate." All the other values (different from zero) are considered "weak." We choose to focus on the gross correlation instead of the net correlation (e. g. as given by beta regression values) and to avoid techniques of data reduction applied to the variables (e.g. factor analysis). These choices are made in order to adopt a purely descriptive (and not inferential) analysis. Our question is not if a specific independent variable (one of the variables introduced before) causes our dependent variable (the propensity to be included in a determinate cluster), rather than if the correlation between a specific descriptive variable and a cluster propensity exists. In a descriptive perspective, the causal mechanism behind the correlation is only marginal and gross effects are more important than net ones.

\section{$5 \quad$ Results and discussion}

\subsection{Cluster identification}

We apply cluster analysis considering the 26 Swiss cantons as units and a wide set of variables referring to cantonal labor markets and economies (see section 4.1) to define the clusters.

Starting from the distance matrix, we calculate the weighted Silhouette width and the Hubert $\mathrm{C}$ index trends. Both these measures reveal a fist optimization point (i. e. a local maximum) in four clusters (see Figure 1).

Following these indications, we define the propensity of each canton to be part of each of these four clusters. Results are summarized in Table 2. The last column on the right defines the cluster membership according to a threshold of $50 \%$. This means that each cluster collects all the cantons that have a probability of $50 \%$ or more to be included. Only Zug fails to meet this threshold for all the clusters. It is thus recorded as an outlier. 
Figure $1 \quad$ Weighted silhouette width (left-hand scale) and
Hubert C Index (right-hand scale) trends

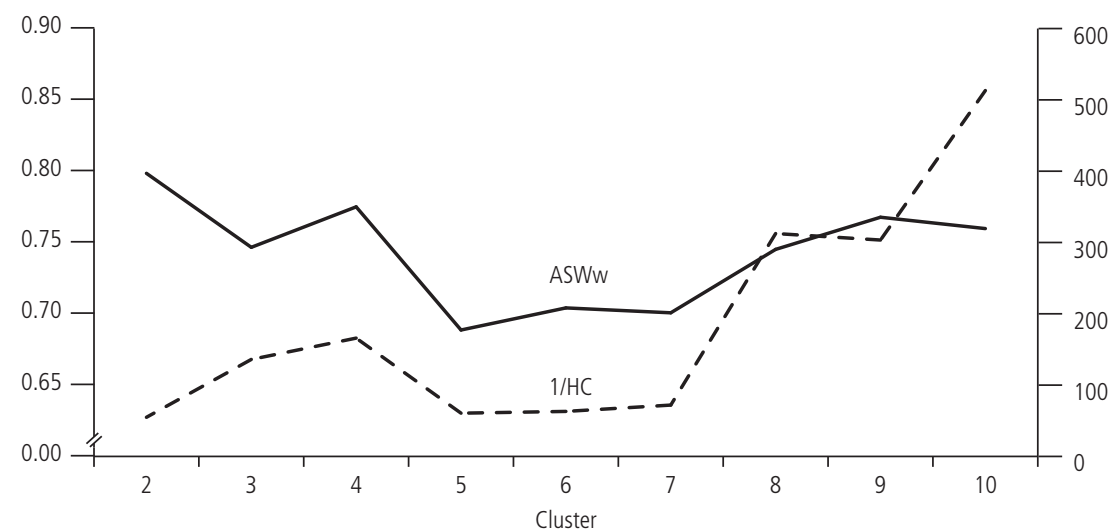

Notes:Weighted Average Silhouette width with Euclidean distances (solid line), and reciprocal of the Hubert C Index (dashed line). Source: FSO's interactive database (STAT-TAB) (2008-2015), own calculations.

We test the cluster attribution described in the last column of Table 2 with a robust procedure based on Ward/PAM hard clustering (Studer 2013). Few preliminary operations are necessary before the comparison. First, we remove the threshold of $50 \%$. Then, we use the highest probability recorded by each canton to decide to which cluster it has to be assigned. This operation eliminates the outliers. Therefore, the canton of Zug is grouped in cluster 4, as we observe the propensity to be included in this cluster to be the highest for this canton. This operation makes it possible to compare our output with the output of the Ward/PAM clustering as this last technique does not accept outliers. The test reveals a perfect correspondence between the outputs given by our procedure (with Zug in cluster 4) and the output given by the Ward/PAM clustering. This result supports the robustness of our procedure and underlines the advantages of using it. Using a fuzzy clustering, we can easily identify the outliers, and describe the "position" of every canton inside the clusters. For example, the canton of Ticino is very well integrated in cluster $2(91.1 \%)$ while Schaffhausen is only marginally part of this cluster $(50.6 \%)$.

Returning to Table 2, we observe that clusters 1 and 2 collect the vast majority of the cantons while cluster 3 only includes Basel-Stadt and cluster 4 only includes two cantons, Geneva and Zurich. On a strictly technical level, Zug is the only outlier. Nevertheless, clusters 3 and 4 are so small that the cantons that they include are, as well, isolated from all the others. Even if, on the technical level, they are not "outliers," each of them represents a unique situation in the Swiss context. We, therefore, decide to keep clusters 1 and 2, while grouping the remaining four cantons in a common group of "unique cases." The consequence of this operation is the following typology: 
Table 2 Propensity of each canton to be part of the four defined clusters

\begin{tabular}{l|rrccc}
\hline Canton & Cluster 1 (\%) & Cluster 2 (\%) & Cluster 3 (\%) & Cluster 4 (\%) & $\begin{array}{c}\text { Cluster } \\
\text { attribution }\end{array}$ \\
\hline Aargau (AG) & 12.7 & 83.0 & 1.2 & 3.2 & 2 \\
Appenzell Inn. (Al) & 78.0 & 15.1 & 2.1 & 4.7 & 1 \\
Appenzell Aus. (AR) & 73.8 & 17.6 & 2.7 & 5.9 & 1 \\
Bern (BE) & 6.6 & 90.3 & 0.8 & 2.4 & 2 \\
Basel-Land. (BL) & 12.8 & 78.9 & 2.0 & 6.3 & 2 \\
Basel-Stadt (BS) & 0.3 & 0.3 & 98.8 & 0.6 & 3 \\
Fribourg (FR) & 76.7 & 15.9 & 2.3 & 5.1 & 1 \\
Geneva (GE) & 3.7 & 4.9 & 3.8 & 87.6 & 4 \\
Glarus (GL) & 74.4 & 20.5 & 1.5 & 3.6 & 1 \\
Graubünden (GR) & 62.0 & 31.5 & 1.9 & 4.7 & 1 \\
Jura (JU) & 84.8 & 11.6 & 1.1 & 2.5 & 1 \\
Luzern (LU) & 51.6 & 41.0 & 2.1 & 5.3 & 1 \\
Neuchâtel (NE) & 14.8 & 74.7 & 2.5 & 8.0 & 2 \\
Nidwalden (NW) & 71.1 & 23.4 & 1.6 & 3.9 & 1 \\
Obwalden (OW) & 77.8 & 17.6 & 1.3 & 3.3 & 1 \\
St. Gallen (SG) & 9.7 & 86.7 & 0.9 & 2.6 & 2 \\
Schaffhausen (SH) & 21.4 & 50.6 & 5.8 & 22.2 & 2 \\
Solothurn (SO) & 59.3 & 33.9 & 1.9 & 4.9 & 1 \\
Schwyz (SZ) & 86.2 & 10.1 & 1.1 & 2.6 & 1 \\
Thurgau (TG) & 85.5 & 11.0 & 1.0 & 2.4 & 1 \\
Ticino (TI) & 6.3 & 91.1 & 0.7 & 1.9 & 2 \\
Uri (UR) & 71.8 & 18.8 & 3.0 & 6.4 & 1 \\
Vaud (VD) & 5.8 & 91.6 & 0.7 & 1.9 & 2 \\
Valais (VS) & 85.5 & 10.5 & 1.2 & 2.8 & 1 \\
Zug (ZG) & 11.3 & 13.7 & 29.2 & 45.8 & Outlier \\
Zürich (ZH) & 10.8 & 16.2 & 6.5 & 66.5 & 4 \\
\hline Soure: FSO's nt. & & & & \\
\hline
\end{tabular}

Source: FSO's interactive database (STAT-TAB) (2008-2015), own calculations.

, Group Alpha collects the cantons with a high probability to be included in cluster 1

, Group Beta collects the cantons with a high probability to be included in cluster 2

, The remaining four cantons are unique cases that are discussed separately

Figure 2 summarizes the clusters considering the new structuration. The Y-axis indicates the probability to be included in cluster 1 while the $\mathrm{X}$-axis reports the probability to be included in cluster 2 . There are three points of attraction. (a) The upper-left corner, i. e. the "center" of cluster 1. In Figure 2, this position indicates a hypothetical situation showing a probability of $100 \%$ to be included in cluster 1 . (b) The lower-right corner, i. e. the "center" of cluster 2. In Figure 2, this position indicates a hypothetical situation showing a probability of $100 \%$ to be included in 
cluster 2. (c) The lower-left corner that indicated a hypothetical situation showing a probability of $0 \%$ to be included both in clusters 1 and 2 . The thick lines indicate the $50 \%$ thresholds.

Figure 2 Group definition according to the propensity to be in cluster 1 and 2

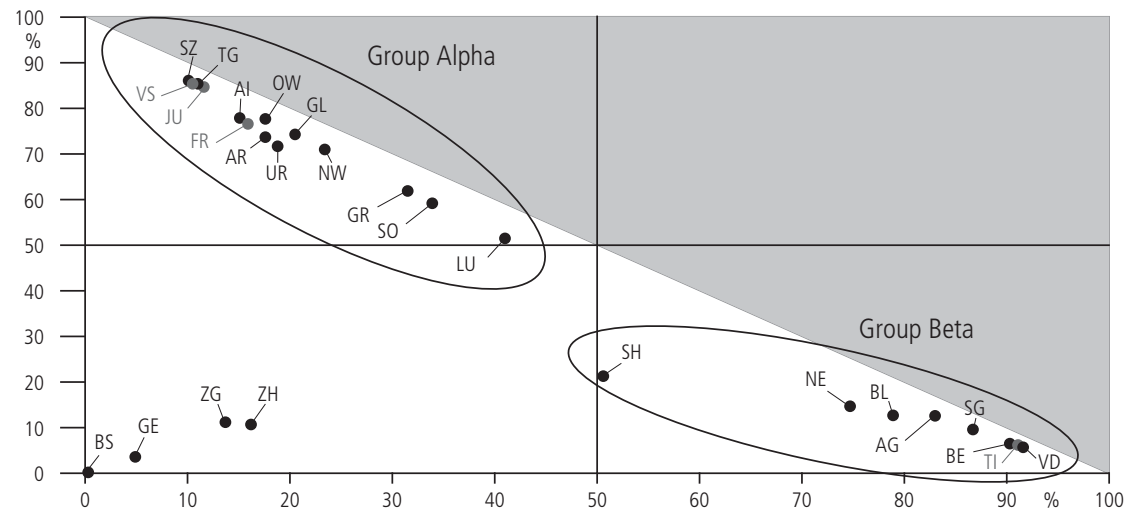

Source: FSO's interactive database (STAT-TAB) (2008-2015), own calculations.

In Figure 2, we also observe the internal structure of each group. Some cantons almost perfectly represent the group and can be taken as representatives. They are situated next to the corners. Others are almost outliers and are visualized at the center of the figure. Group Alpha includes 14 cantons mainly from the mountain areas of Switzerland. Four cantons appear to be the most representative of this group: Schwyz, Valais, Jura, Thurgau. All these cantons have a probability higher than $85 \%$ to be included in cluster 1 . The other cantons have a lower probability. In particular, Graubünden (62.0\%), Solothurn (59.3\%) and Luzern (51.6\%) fit only marginally into this group. Group Beta collects eight cantons. Three cantons appear representative of this group: Vaud, Ticino, Bern. All these cantons have a probability higher than $90 \%$ to be included in cluster 2 . The other cantons have a lower probability. Particularly, Schaffhausen (50.6\%) fits only marginally into this group. Referring to the outliers, we use the probabilities to be included in Alpha and Beta to drive the discussion. All the other cantons have a low probability of being included in the two previous groups. This percentage passes from $16.2 \%$ (between Zurich and group Beta) to 0.3\% (between Basel-Stadt and group Alpha). These values mean that all these cantons are very different from the identified groups. As it is graphically represented in Figure 2, they are almost perfectly equidistant from groups Alpha and Beta, and far from both the thresholds. Considering this (technical) characteristic, these cantons are very similar. In addition, a more specific analysis 
stresses that all these cantons have a similar urban structure. In particular, they are all strictly connected to metropolitan areas (including Zug, which is almost entirely comprised of Zurich's urban area). Therefore, we decide to organize the discussion of these cantons starting from a general description of them, as if they belonged to a single group (Gamma) and, then, by stressing the differences (when present).

\subsection{Variables incidence in the groups}

Our description relies on the analysis of the distribution of the variables used to define the clusters. This analysis links each group to a set of socio-economic and labor market characteristics allowing their description. As all the variables involved are fully numerical, we can calculate the correlation between the propensity to be included in a group and the incidence of the variables used to build them. This information gives us the incidence of each variable inside each group. Strong effects $(\geq 0.7)$ have a gray background and are in bold, moderate effects $(\geq 0.3)$ are in bold only.

Table 3

Correlation between groups and defining factors

\begin{tabular}{l|c|c|c}
\hline & Group Alpha & Group Beta & Group Gamma \\
\hline Gross Domestic Product (GDP) per capita & -0.65 & -0.15 & 0.91 \\
GDP variance & -0.10 & 0.16 & -0.06 \\
Gini Index & -0.16 & -0.24 & 0.44 \\
Correlation between national and cantonal GDP & -0.29 & 0.30 & 0.00 \\
Small and Medium Enterprises (SMEs) presence & 0.56 & 0.03 & -0.67 \\
High-tech enterprises presence & -0.71 & 0.03 & 0.78 \\
Tax pressure & -0.34 & 0.26 & 0.11 \\
Unemployment rate & -0.53 & 0.24 & 0.35 \\
Young unemployment rate & -0.53 & 0.27 & 0.32 \\
Long-time unemployment rate & -0.51 & 0.28 & 0.28 \\
Women presence in the workforce & -0.38 & -0.06 & 0.50 \\
Cross-border workers in the workforce & -0.50 & 0.07 & 0.50 \\
Cantonal labor market attractiveness & -0.60 & -0.12 & 0.82 \\
\hline
\end{tabular}

Source: FSO's interactive database (STAT-TAB) (2008-2015), own calculations.

A general view on Table 3 shows how all the variables record the minimum moderate correlations with at least one of the groups, except from GDP variance. Groups Alpha and Gamma are opposed. They never have a significant coefficient with the same sign. If the coefficient in group Alpha is positive, it's corresponding coefficient in group Gamma is negative, and vice-versa. The group Beta appears to be intermediate between the former two. Due to this intermediate position, the group Beta records a single moderate effect referring to the correlation between national and cantonal GDP. Nevertheless, the coefficient referring to long-term and young 
unemployment rates is just below the threshold of a moderate effect and can be discussed as marginally relevant.

\subsection{Organization and interpretation of the groups}

Starting from the elements introduced in the last section, we propose an interpretation of the three identified groups:

Group Alpha is composed of marginal labor markets. These cantons have poor economies (for Swiss standards) with a weak relation with the national economic trend. The labor market is mainly based on small and medium enterprises active in low-technology sectors. These cantons are weakly attractive: They record a high number of outgoing commuters and a low number of incoming commuters. Among the 14 cantons of this group, none of them have more incoming commuters than outgoing commuters. Unemployment is low or very low in all its components (general, young and long-term), and workforce records a low presence of women and cross-border workers. The representative cantons are Schwyz, Valais, Jura and Thurgau. For example, the canton of Schwyz records the second least attractive labor market and the second highest presence of small and medium enterprises (97\%). Unemployment is very low (1.6\%) and cross-border workers are almost completely absent $(0.1 \%)$.

Group Beta includes multicenter labor markets. The interpretation of this group is slightly trickier, as it records almost only weak correlations with the considered variables. This situation is also due to the intermediate position of this group with reference to the other two groups of our typology. The economy of these cantons is the most connected to the national one. These cantons have a very complex and differentiated economic fabric that includes enterprises focused on international, national and local markets. This structure is the most sensitive to changes in the national economy. On one side, the presence of enterprises centered on international markets is not enough to protect the cantonal economy from national fluctuations given by changes in consumption habits or new economic policies. On the other side, medium and large enterprises cannot only rely on local consumers and need a national market to prosper. In addition to these elements, cantons in this group have a marginal propensity to have high values of unemployment and tax pressure. The distribution of wealth in these cantons is also the most egalitarian, but with very low differences to the cantons in group Alpha. The representative cantons are Vaud and Ticino. These cantons are relatively vast areas with multiple attraction centers. Vaud, for example, has Lausanne, Vevey, Nyon, and others). In addition, the correlation between Vaud and Swiss GDP trends is 0.91 , close to a perfect correlation. Vaud has the highest index of tax pressure and the third highest rate of unemployment (4.6\%). 
Group Gamma includes only cantons that coincide with metropolitan areas. These areas are very attractive labor markets. Each of these cantons is a unique situation in the Swiss context. The comparison among these clusters shows that Geneva and Basel-Stadt are very similar, while Zurich and, especially, Zug record few differences. For example, cross-border workers are largely present in Geneva and Basel, while much less in Zurich and Zug. In addition, the unemployment rate and the index recording the presence of innovative enterprises have medium values for Zug, while it is high for the other three cantons. Nevertheless, our results also show that they share some important characteristics, and, to some extent, can be discussed together. All these cantons have rich, less egalitarian and attractive economies that are largely independent from the national context. They occupy the first four places if we rank the cantons by GDP per capita, and are the only areas to have a difference between incoming and outgoing workers that is largely positive. Large enterprises are almost twice as present in this group than in the rest of the country $(23.1 \%$ against $12.7 \%$ ) and the index describing the presence of high-tech companies has very high values (except for Zug, which has medium values).

\section{An empirical test of our typology}

\subsection{Objectives}

In this section, we have a double objective: performing a test of the heuristic power of our typology and showing an example of an application of it. We present a descriptive analysis of a simple subject in order to show how our typology can be used to create hypotheses starting from the characteristics of each group and transforming it into a variable that can be easily included in a statistical analysis.

In our analyses, we study the flow of workers that move to another area to begin a new job. Using the characteristics of the three types described by our typology, we delineate two main hypotheses:

1. The first hypothesis refers to the general work-related relocations:

a. We expect many workers to move to the cantons defined as "attractive labor market" and only few workers to move from these cantons.

b. We expect an opposite trend for "marginal labor market": few incoming workers and many outgoing workers.

c. We expect "multicenter labor markets" to have intermediate characteristics with respect to "attractive labor markets" and "marginal labor market." Consequently, we expect "multicenter labor markets" to record an incoming and outgoing flow of workers with comparable sizes. 
2. The second hypothesis refers to workers' type of jobs. We expect the "attractive labor market" to mainly attract workers in upper-level jobs and the "marginal labor market" to attract workers employed in elementary occupations. Once again, we expect the "multicenter labor markets" to be in an intermediate position.

\subsection{Data and variables used for the test}

We use data coming from the calendar questionnaire of the first wave of the third sample (SHP III) of the Swiss Household Panel (Voorpostel et al. 2015). These data have few problems; specifically, they do not report individuals' work addresses. Nevertheless, unlike other data, the Swiss Household Panel is not used to create official statistics of the workforce. We thus avoid the risk of endogeneity. Given the limited information on the place of work, we include in our sample the individuals who simultaneously indicate a change of residence and work status in the 2000-2012 period. People coming from abroad or moving abroad are not included in the sample. We measure the residence at the cantonal level and the work status, using the International Standard Classification of Occupations (4-digit ISCO-88) codes. We consider the transitions work-to-work or inactivity-to-work, but not the transitions work-to-inactivity. The size of our sample is 84 units. The Swiss Household Panel provides the weights for longitudinal use (Voorpostel et al. 2014). The weights are corrected to compensate for the geographic distribution of the population which, in the Swiss Household Panel, is based on the NUTS areas (see section 3.2). In the descriptive part, we recode the 4-digit ISCO-88 code in a three-level definition of the work position. In this last part of the analysis, a very thin granularity of the measure would make the results less clear, due to the elevated number of possible occupations. Our classification of the job positions includes:

, “Upper-level jobs" i.e. "legislators, senior officials, and managers" and "professionals"

"Medium level jobs" i. e. "technicians and associate professionals," "clerks," "service workers and shop and market sales workers," "skilled agricultural and fishery workers," "craft and related trades workers," and "plant and machine operators and assemblers"

, "Elementary occupations" i. e. the equivalent ISCO category

\subsection{Worker flows among the groups}

Table 4 shows the subdivision of incoming and outgoing workers referring to the groups of our typologies for the 2000-2012 period.

We observe "multicenter labor markets" to have the highest share of both incoming and outgoing workers (over $40 \%$ in both cases). Multicenter labor markets appear to be a fluid area with many workers moving to and from these 
Table 4 Incoming and outgoing workers per labor market type

\begin{tabular}{lccc}
\hline Labor market type & Attraction (\%) & Repulsion (\%) & $\begin{array}{c}\text { Net flow } \\
\text { (in percentage points) }\end{array}$ \\
\hline Marginal labor markets & 21.9 & 39.8 & -18.0 \\
Multicenter labor markets & 47.3 & 42.4 & 4.9 \\
Attractive labor markets & 30.9 & 17.8 & 13.1 \\
\hline
\end{tabular}

Source: Swiss Houshold Panel (2000-2012), own calculations.

cantons. "Attractive labor markets" appear to be an area of attraction, as they collect almost $30 \%$ of the incoming workers and less than a fifth of the outgoing workers. Marginal labor markets are in the opposite situation. These areas collect around a fifth of the incoming workers and almost $40 \%$ of the outgoing workers.

All these observations support our hypotheses. Workers move in the direction of "attractive labor markets" and, even more significantly, towards "multicenter labor markets." Nevertheless, the incoming flow of workers in "multicenter labor markets" is compensated by a large share of workers leaving these areas. We expected even fewer workers to leave "attractive labor markets." Nevertheless, the number of outgoing workers is largely surpassed by incoming workers. Coherently with the characteristics of this group, "marginal labor markets" are a source of workers and, only marginally, a destination.

Figure 3 describes the aforementioned flow of workers, but we split the sample according to the job type. We only excluded two cases that transited to a low-hours part-time position that are hard to place in a socio-occupational scale.

Figure 3 Incoming and outgoing workers per labor market type and job type

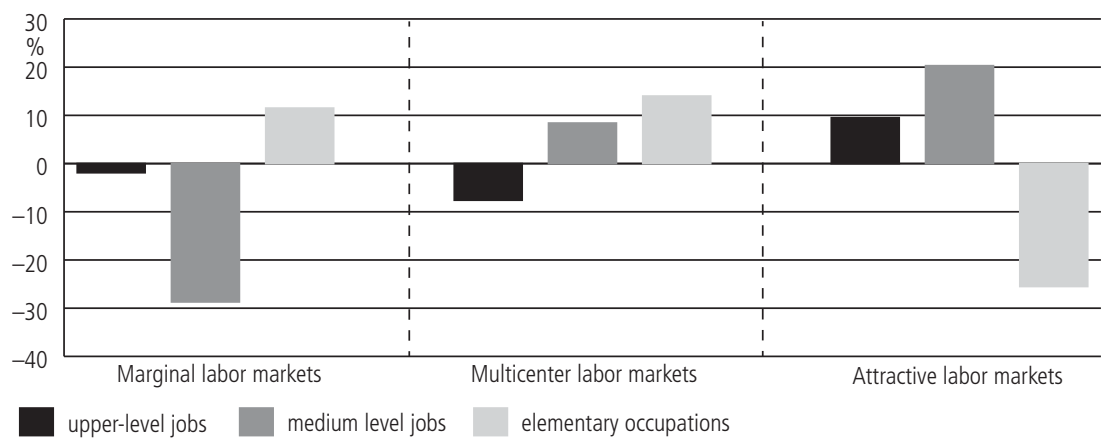

Source: Swiss Household Panel (2000-2012), own calculations.

Attractive labor markets are the only group in which we observe more incoming workers than outgoing workers in upper-level jobs. The opposite situation defines the marginal labor markets group. Only workers in elementary occupations have a 
positive net flow. Multicenter labor markets are in an intermediate position. These observations support the hypotheses we made on the basis of the characteristics of each group included in our typology. Attractive labor markets have a higher presence of high-tech and international companies, which often need a highly-qualified workforce. The opposite is true for marginal labor markets, which mainly attract low qualified workers, coherently with the needs of local-based companies active in sectors with low added value.

The descriptive analyses we introduced show that our typology can be easily introduced into a study of labor market and economic issues, bringing elements on Swiss regional differences and proposing interpretative frames.

\section{Conclusion}

Switzerland is a complex territorial context. The historical formation of the nation is made up by successive aggregations of small territories that gave birth to a highly decentered institutional structure composed by 26 cantons. Given the high number of cantons and the small size of many of them, the use of cantons as territorial units in the empirical analysis can create problems for sample-based analyses. Many samples are too small in size to include a sufficient number of units to support a robust analysis that embraces all the cantons. As a consequence, many researchers prefer using more parsimonious typologies. The most frequently used typologies are the Swiss Vast Regions and the Swiss linguistic areas. Despite their large use, these typologies bring a low added value to socio-economic and labor market studies, as they rely on factors that are only partially related to the economic fabric of the Swiss regions. Other typologies based on economic factors (Battaglini and Giraud 2003; Flückiger et al. 2006) are either constructed on few variables or do not cover the entire Swiss territory. In this paper, we proposed a new typology, based on a large set of variables that refer to economic and labor market characteristics of each canton. We use cluster analysis to aggregate the cantons and Pearson's correlation index to describe the resulting clusters. Our typology defines three groups:

, Group Alpha, which includes marginal labor markets. This group contains 14 cantons and collects local-based economies that are poorly attractive for workers of other territories (in Switzerland or abroad).

, Group Beta, which includes multicenter labor markets. This group contains eight cantons that have a relatively large urbanized territory with many attractive areas (usually the biggest cities). The compresence of territories with different economic structures produces a general situation that is intermediate between the other two groups.

, Group Gamma, which includes highly attractive metropolitan labor markets. This group is substantially quite homogeneous, as it collects four cantons 
corresponding to 3 large Swiss urban areas. These labor markets have only marginal boundaries with the local economy, due to the presence of international and high-tech companies. They strongly attract commuters from the other cantons and, in some cases, the nearby European regions.

Each group represents a context with consistent socio-economic characteristics that can be used as explanatory or control variable in researches aimed at considering the general differences in Swiss labor markets. To give an example of its use, we use data from the Swiss Household Panel to analyze the flows of workers moving to another canton to start a new job. Our results show how the characteristics of our typology can provide elements useful to explain this phenomenon. As we have shown in section 6, work-related mobility of workers in different job types can be partially explained by the regional differences in the Swiss labor market that are described in our typology. More generally, a vast set of socio-economic and labor market researches can benefit from our typology. The most used typologies that describe the Swiss territory only marginally connect with the regional economic structure. In reverse, our typology provides a description of the economic fabric of each region that can bring a substantive added value to the results. In addition, our test illustrates how our typology can be easily applied to other studies. The variable that describes our typology can be easily included in a descriptive analysis, in a regression model, and in many other empirical approaches, also in presence of small samples. Differently from cantons, which are numerous and very diverse in size, our typology has a parsimonious structure composed by only three groups that refer to three large shares of the Swiss population.

Given these elements, we estimate that the proposed typology can become a useful tool for other research and contribute to the need of a territorial categorization of Swiss regions according to economic and labor market factors.

\section{References}

Barro, Robert. 2000. Inequality and Growth in a Panel of Countries. Journal of Economic Growth 32 (March): 5-32.

Battaglini, Monica and Olivier Giraud. 2003. Policy Styles and the Swiss Executive Federalism: Comparing Diverging Styles of Cantonal Implementation of the Federal Law on Unemployment. Swiss Political Science Review 9(1): 285-308, http://doi.wiley.com/10.1002/j.1662-6370.2003. tb00408.x (20.04.2016).

Bertozzi, Fabio, Giuliano Bonoli, and Benoit Gay-des-Combes. 2005. La réforme de l'Etat social en Suisse: Vieillissement, emploi, conflit travail-famille. Lausanne: Presses polytechniques et universitaires romandes.

Bertschy, Kathrin, Philipp Walker, Annick Baeriswyl, and Michael Marti. 2014. Lohndiskriminierung beim Berufseinstieg. Eine quantitative Analyse für die Schweiz. Swiss Journal of Sociology 40(2): 279-305. 
Bonoli, Giuliano. 2014. Employers' Attitudes Towards Long-Term Unemployed People and the Role of Activation in Switzerland. International Journal of Social Welfare 23(4): 421-430.

Bruttin, Alexis. 1997. Le territoire des politiques d'aide aux chômeurs: Le cas de l'agglomération transfrontalière de Genève-Annemasse. Geneva: Université de Genève.

Chaix, Basile, Juan Merlo, and Pierre Chauvin. 2005. Comparison of a Spatial Approach With the Multilevel Approach for Investigating Place Effects on Health: The Example of Healthcare Utilisation in France. Journal of Epidemiology and Community Health 59: 517-526.

Curti, Monica and Erika Meins. 1999. Politiques suisses du marché du travail - Différences résultant de sa mise en application au niveau du service de l'emploi. La Vie Economique 2: 64-70.

De Coulon, Augustin. 1999. Disparité régionale du chômage: Population étrangère et courbe de Beveridge suisse. Swiss Journal of Economics and Statistics 135(2): 165-185.

Feld, Lars P. and Marcel R. Savioz. 2000. Cantonal and Regional Unemployment in Switzerland: A Dynamic Macroeconomic Panel Analysis. Zeitschrift für Volkswirtschaft und Statistik 136(1996): 463-483.

Filippini, Paolo. 1998. Regional Unemployment Disparities: The Case of Swiss Cantons. Zurich: vdf.

Flückiger, Yves, Pierre Kempeneers, Joseph Deutsch, Jaques Silber, and Stephen Bazen. 2006. Analyse des différences régionales de chômage. Neuchâtel: FSO (Swiss Federal Statistical Office).

Flückiger, Yves, Alain Schönenberger, and Milad Zarinnejadan. 1986. Measuring Different Types of Unemployment in Switzerland. Zeitschrift für Volkswirtschaft und Statistik 1: 17-35.

Flückiger, Yves and Anatoli Vassiliev. 2002. Les raisons des différences de chômage entre Genève et le reste de la Suisse. Zeitschrift für Volkswirtschaft und Statistik 138(4): 387-410.

FSO (Swiss Federal Statistical Office). 2008. NOGA 2008: General Classification of Economic Activities: Introduction. Neuchâtel: FSO, http://www.bfs.admin.ch/bfs/portal/en/index/news/publikationen. html?publicationID=3455 (13.10.2015).

Gerfin, Michael and Michael Lechner. 2002. A Microeconometric Evaluation of the Active Labour Market Policy in Switzerland. The Economic Journal 112(482): 854-893.

Giraud, Olivier and Monica Battaglini. 2004. Mise en œuvre des politiques pour l'emploi et pouvoir régional: Le poids des réseaux sociaux et politiques. Swiss Journal of Sociology 30(3): 363-379.

Giriens, Pierre-Yves and Julien Staufer. 1999. Deuxième révision de la loi sur l'assurance-chômage: Genèse d'un compromis. Pp. 105-143 in Globalisation, néo-libéralisme et politiques publiques dans la Suisse des années 90, edited by André Mach. Zurich: Seismo.

Giugni, Marco, Michel Berclaz, and Katharina Fuglister. 2014. La politique contestataire du chômage en Suisse. Zurich and Geneva: Seismo.

Goebel, Viktor and Yvonne Ehrensperger. 2009. Disparités régionales en Suisse: Indicateurs clés. Neuchâtel: FSO (Swiss Federal Statistical Office).

Guillet, Delphine, Johanna Huber, Laura Ravazzini, and Christian Suter. 2016. Conditions de travail dans les administrations cantonales en Suisse, 1991-2012. MAPS Working Paper Series 4-2016, University of Neuchâtel, https://www.unine.ch/files/live/sites/maps/files/shared/documents/wp/ WP-4_2016_Guillet_Huber_Ravazzini_Suter.pdf (26.09.2016).

Hubert, Lawrence J. and Joel R. Levin. 1976. A General Statistical Framework for Assessing Categorical Clustering in Free Recall. Psychological Bulletin 83(6): 1072-1080.

Jeanneret, Barbara and Viktor Goebel. 2012. Les disparités régionales en Suisse. Neuchâtel: FSO.

Joly, Régis, Jean-Christian Lambelet, and Cédric Tille. 1993. Origines et causes de la montée du chômage en Suisse. Lausanne: UNIL / HEC.

Kaufman, Leonard and Peter J. Rousseeuw. 1990. Finding Groups in Data: An Introduction to Cluster Analysis. New York: John Wiley \& Sons. 
Kubiszewski, Ida, Robert Costanza, Carol Franco, Philip Lawn, John Talberth, Tim Jackson, and Camille Aylmer. 2013. Beyond GDP: Measuring and Achieving Global Genuine Progress. Ecological Economics 93: 57-68, http://dx.doi.org/10.1016/j.ecolecon.2013.04.019 (26.09.2016).

Lebert, Florence. 2014. Der Einfluss der Arbeitsbelastungen auf die Lebenszufriedenheit unter Berücksichtigung des Lebenspartners beziehungsweise der Lebenpartnerin. Swiss Journal of Sociology 40(3): 451-474.

Le Goff, Jean-Marie. 2005. Articulation entre la vie familiale et la vie professionnelle. Pp. 239-280 in Maternité et parcours de vie, edited by Jean-Marie Le Goff and Claudine Sauvain-Dugerdil. Bern: Peter Lang.

OECD. 2014. Mieux travailler avec l'âge: Suisse, évaluation et principales recommandations. Paris: OCDE.

OECD. 2013. EPL Database, Update 2013. Paris: OCDE.

Oesch, Daniel and Olivier Lipps. 2012. Does Unemployment Hurt Less If There Is More of It Around? A Panel Analysis of Life Satisfaction in Germany and Switzerland. European Sociological Review 29(5): 955-967.

Perret, Virgile, Olivier Giraud, Marc Helbing, and Monica Battaglini. 2007. Les cantons suisses face au chômage. Paris: L'Harmattan.

Pintaldi, Federica. 2003. I dati ecologici nella ricerca sociale. Roma: Carocci.

Ravalet, Emmanuel, Yann Dubois, and Vincent Kaufmann. 2014. Grandes mobilités et accès à l'emploi. Reflets et perspectives de la vie économique 80(3): 57-76.

Rousseeuw, Peter J. 1987. Silhouettes: A Graphical Aid to the Interpretation and Validation of Cluster Analysis. Journal of Computational and Applied Mathematics 20: 53-65.

Sacchi, Stefan and Thomas Meyer. 2016. Übergangslosungen beim Eintritt in die Schweizer Berufsbildung: Brückenschlag oder Sackgasse? Swiss Journal of Sociology 42(1): 9-39.

Savitz, Natalya Verbitsky and Stephen W. Raudenbush. 2009. Exploiting Spatial Dependence to Improve Measurement of Neighborhood Social Processes. Sociological Methodology 39(1): 151-183.

Schuler, Martin, Pierre Dessemontet, and Dominique Joye. 2005. Les niveaux géographiques de la Suisse. Neuchâtel: FSO.

Sheldon, George. 2013. Unemployment Persistence, Duration Dependence, and Long-Term Unemployment: A Markov Perspective. Basel: University of Basel.

Stiglitz, Joseph E., Amartya Sen, and Jean-Paul Fitoussi. 2010. Mismeasuring Our Lives: Why GDP Doesn't Add Up. New York: New Press.

Studer, Matthias (2013). WeightedCluster Library Manual: A Practical Guide to Creating Typologies of Trajectories in the Social Sciences With R. LIVES Working Papers, 24

Voorpostel, Marieke Robin Tillmann, Florence Lebert, Ursina Kuhn, Oliver Lipps, Valérie-Anne Ryser, Flurina Schmid, Erika Antal, and Boris Wernli. 2014. Swiss Household Panel Userguide (1999-2013), Wave 15, December 2014. Lausanne: FORS.

Voorpostel, Marieke, Robin Tillmann, Florence Lebert, Ursina Kuhn, Oliver Lipps, Erika Antal, ValérieAnne Ryser, Flurina Schmid, Boris Wernli, and Gian-Andrea Monsch. 2015. Swiss Household Panel: User Guide (1999-2015). Lausanne: FORS, http://forscenter.ch/wp-content/uploads/2013/11/ Getting_started_with_SHP_data.pdf (28.09.2016).

Ward, Michael D. 2002. Location, Location, Location: An MCMC Approach to Modeling the Spatial Context of War and Peace. Political Analysis 10: 244-260, http://pan.oxfordjournals.org/content/10/3/244.abstract (09.03.2015).

Wernli, Boris and Caroline Henchoz. 2015. Les conséquences financièrs du départ du foyer parental. Une analyse longitudinale des données du Panel suisse de ménages. Swiss Journal of Sociology 41(2): 311-328. 